OPEN ACCESS

Edited by: Sebastian Kelle, Deutsches Herzzentrum

Berlin, Germany

Reviewed by:

Wen-Yi Yang

Shanghai Jiao Tong University, China

Jing Wang,

Wuhan University, China

*Correspondence:

Yu Cai

caiy_kf@163.com

Haotian Gu

haotian.gu@kcl.ac.uk

†These authors share first authorship

¥These authors share senior authorship

Specialty section

This article was submitted to

Cardiovascular Imaging

a section of the journal

Frontiers in Cardiovascular Medicine

Received: 06 April 2021

Accepted: 21 June 2021

Published: 20 July 2021

Citation:

Zhu P, Wang Z, Guo X, Feng Z,

Chen $C$, Zheng A, Gu $\mathrm{H}$ and Cai $Y$

(2021) Pulmonary Rehabilitation

Accelerates the Recovery of

Pulmonary Function in Patients With

COVID-19.

Front. Cardiovasc. Med. 8:691609.

doi: 10.3389/fcvm.2021.691609

\section{Pulmonary Rehabilitation} Accelerates the Recovery of Pulmonary Function in Patients With COVID-19

\author{
Pengfei Zhu ${ }^{1+}$, Zhengchao Wang ${ }^{2+}$, Xiaomi Guo ${ }^{3 \dagger}$, Zhiyong Feng ${ }^{4}$, Chaochao Chen ${ }^{4}$, \\ Ai Zheng ${ }^{4}$, Haotian $\mathrm{Gu}^{5 * \pm}$ and Yu Cai ${ }^{4 * \pm}$
}

\begin{abstract}
${ }^{1}$ Department of Cardiology, Wuhan Fourth Hospital, Puai Hospital, Tongji Medical College, Huazhong University of Science and Technology, Wuhan, China, ${ }^{2}$ Tongji Hospital, Tongji Medical College, Huazhong University of Science and Technology, Wuhan, China, ${ }^{3}$ Department of Ultrasound, Wuhan Asia General Hospital, Wuhan, China, ${ }^{4}$ Department of Rehabilitation, Wuhan Fourth Hospital, Puai Hospital, Tongji Medical College, Huazhong University of Science and Technology, Wuhan, China, ${ }^{5}$ British Heart Foundation Centre of Research Excellence, King's College London, London, United Kingdom
\end{abstract}

Objectives: To evaluate the effect of in-hospital pulmonary rehabilitation (PR) on short-term pulmonary functional recovery in patients with COVID-19.

Methods: Patients with COVID-19 $(n=123)$ were divided into two groups (PR group or Control group) according to recipient of pulmonary rehabilitation. Six-min walk distance $(6 \mathrm{MW})$, heart rate $(\mathrm{HR})$, forced vital capacity $(\mathrm{FVC})$, forced expiratory volume in $1 \mathrm{~s}$ $\left(F E V_{1}\right)$, diffusing capacity of the lung for carbon monoxide ( $\left.\mathrm{DL}_{\mathrm{CO}}\right)$, and CT scanning were measured at the time of discharge, 1, 4, 12, and 24 weeks.

Results: At week one, both PR group and Control group showed no significant changes in pulmonary function. At 4 and 12 weeks, 6MW, HR, FVC, FEV 1 , and DLCo improved significantly in both groups. However, the improvement in the PR group was greater than the Control group. Pulmonary function in the PR group returned to normal at 4 weeks [FVC (\% predicted, PR vs. Control): $86.27 \pm 9.14$ vs. $78.87 \pm 7.55$; FEV1 (\% predicted, PR vs. Control) $88.76 \pm 6.22$ vs. $78.96 \pm 6.91$; DLCO (\% predicted, PR vs. Control): $87.27 \pm 6.20$ vs. $77.78 \pm 5.85$ ] compared to 12 weeks in the control group [FVC (\% predicted, PR vs. Control): $90.61 \pm 6.05$ vs. $89.96 \pm 4.05$; FEV1 (\% predicted, PR vs. Control) $94.06 \pm 0.43$ vs. $93.85 \pm 5.61$; DLCO (\% predicted, PR vs. Control): $91.99 \pm$ 8.73 vs. $88.57 \pm 5.37]$. Residual lesions on CT disappeared at week 4 in 49 patients in PR group and in 28 patients in control group ( $p=0.0004)$.

Conclusion: Pulmonary rehabilitation could accelerate the recovery of pulmonary function in patients with COVID-19.

Keywords: pulmonary training, corona virus disease 2019, pulmonary function, pulmonary rehabilitation, 2019-nCoV 


\section{INTRODUCTION}

Corona Virus Disease (COVID-19) caused by a novel coronavirus named as Severe Acute Respiratory Syndrome (SARS)-CoV (Corona Virus)-2 has been rapidly occurring the world and is not completely controlled till now $(1,2)$. Transmissions through fecal-oral route and ocular are also considered to be possible while evidences are not sufficient till now $(3,4)$. All age groups are susceptible to SARS-CoV2 , while the elderlies and people with underlying diseases are more likely to develop severe conditions such as severe pneumonia and respiratory failure in a short period of time (2). The therapeutic principles of COVID-19 include general treatment (vital sign monitoring, mechanical ventilation, etc.), drug therapy (anti-infection drugs, traditional Chinese medicine, etc.), pulmonary rehabilitation (PR), nutrition management and mental support.

Pulmonary rehabilitation, as a comprehensive intervention including exercise training, education and behavioral changes that aims to improve the physical and psychological condition in patients with respiratory disease and to promote high longterm quality of life. It has also been confirmed to be an important part of the integrated care strategy for chronic obstructive pulmonary disease (COPD) $(5,6)$. Its positive effects in preoperative pulmonary rehabilitation were also discovered including reducing the sensation of dyspnea, reducing muscle strength loss associated with dyspnea, and improving psychologic states (7). As for infectious disease of respiratory system, Hsieh et al. (8) found that survivors of acute respiratory distress syndrome (ARDS) caused by influenza A (H1N1) who received pulmonary rehabilitation for 2 months had improved pulmonary function, exercise capacity, and quality of life.

Therefore, the aim of present study was to evaluate the effect of in-hospital pulmonary rehabilitation on short-term pulmonary functional recovery in patients with COVID-19.

\section{METHODS}

\section{Patients and Data Collection}

We conducted a perspective observational study in patients with COVID-19.

Participants were recruited from Puai Hospital, Wuhan Forth Hospital and Huazhong University of Science and Technology, and were divided into two groups according to whether patients received in-hospital pulmonary rehabilitation. Patients who underwent in-hospital pulmonary rehabilitation were based on the clinical judgements by attending physicians. No patients were directly involved in the design, planning and conception of this study. Inclusion criteria were: (1) patients with COVID-19; (2) able to receive pulmonary rehabilitation; (3) no co-infection of other pathogene; (4) sign the informed consent. Exclusion criteria include: (1) suffering from high blood pressure, diabetes, or other chronic or basic diseases; (2) COVID-19 recurrence during the follow-up period. (3) infection of other pathogene during the follow-up period. (4) pregnancy before or during the follow-up period. Data were collected at the time of discharge and 1, 4, 12, 24 weeks after discharge. The study was approved by Chinese Clinical Trial Registry (ChiCTR2000031751).

\section{Pulmonary Rehabilitation}

In the PR group, all patients underwent a standardized rehabilitation scheme (ref) when their clinical condition was stable and capable of PR. Detailed PR protocol as follow: (1) allow patients to maintain regular movement, such as chest expansion and ambulation, in the isolation ward for at least $1 \mathrm{~h}$ per day while monitoring heart rate and respiratory rate during movement to avoid overexertion in terms of heart and lung function; (2) provide respiratory control training: Help the patients sit in an upright position to avoid orthopnea. If the patients could not sit upright, lift the head of bed by 60 degrees. Let the patients relax their shoulder muscles by placing one hand on the chest and the other on the abdomen, instruct the patients to deeply breathe in through their nose and breathe out through their mouth to expand the lower chest. (3) pursed lip breathing: Keep the same patient position as with respiratory control. Let the patients breathe in through their nose, hold their breath for $2 \mathrm{~s}$, then deeply breathe out using their abdomen for 3-5s with their mouth pursed as if they are whistling; this increases the expiratory resistance and prolongs the expiratory time. For (2) and (3) above, the patients were trained repeatedly for 10-15 min each and 4 times per day. The patients could train along with light music if possible. If any discomfort occurred, the training should be stopped immediately.

\section{Outcome Measures}

Six-min walk distance (6MW), Heart rate (HR), forced vital capacity (FVC), forced expiratory volume in $1 \mathrm{~s}\left(\mathrm{FEV}_{1}\right)$, and Diffusing capacity of the lung for carbon monoxide $\left(\mathrm{DL}_{\mathrm{CO}}\right)$ were measured. CT scanning was conducted at discharge, 4, and 24 weeks. FVC and $\mathrm{FEV}_{1}$ were measure using spirometry. Spirometry was performed using the Medical Graphics CPXD (Minneapolis, MN, US). Diffusing capacity of the lung for carbon monoxide $\left(\mathrm{DL}_{\mathrm{CO}}\right)$ were assessed using the rebreathe technique and a mass spectrometer (Perkin Elmer, St. Louis, MO, USA) as previously described $(9,10)$. CT scan was conducted using a 64-slice spiral CT machine (NeuSoft, NeuViz64). The CT images was evaluated by two experienced imaging clinicians. If their opinions were different, a third clinician was invited to make the final decision.

\section{Statistical Analysis}

Statistical analysis was completed using SPSS 21.0. Baseline differences between groups were analyzed by Student's $t$-test for continuous data and by the $\chi^{2}$ test for categorical data. Continuous data are expressed as the means \pm SDs, and the normality of distribution was tested by a QQ plot. The data were analyzed using Student's $t$-test and repeated measures analysis of variance (ANOVA). As for repeated measures ANOVA, posthoc test of $p$-value was adopted by Bonferroni correction and effect size was expressed as eta-square. A value of $p<0.05$ was considered statistically significant. Because of a small sample size, $p$-valued between 0.05 and 0.1 was marked with specific value. 


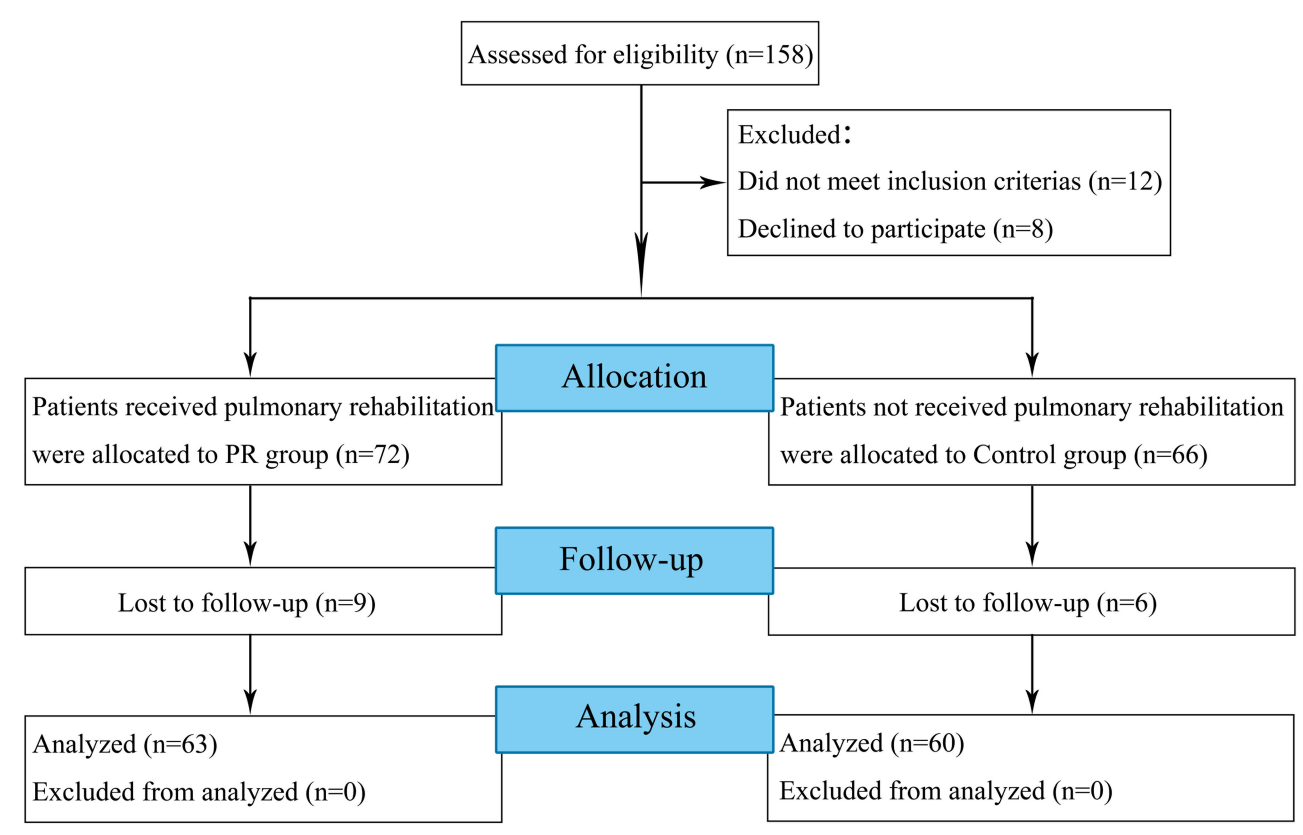

FIGURE 1 | Flow diagram of the study design.

\section{RESULTS}

A total of 158 participants were screened between February 1st 2020 to March 31st 2020, out of whom 20 patients were excluded because of not meeting the inclusion criteria or declined to participate in this study (Figure 1). Fifteen participants were lost to follow-up before 4 weeks follow-up. Baseline demographics were shown in Tables 1-3.

$6 \mathrm{MW}$ and HR were shown in Table 4. At the time of discharge, $6 \mathrm{MW}$ distance in PR group was longer than the Control group and the HR was lower than the Control group, but did not reach significant. At the time of week 1 and 4, there were significant improvements of $6 \mathrm{MW}$ and $\mathrm{HR}$ in PR group compared to those at the time of discharge (week 1: 495.88 \pm 34.67 vs. $470.83 \pm 35.70 p<0.05$ and $83.24 \pm 8.46$ vs. $97.05 \pm 14.24 p<0.001$; week $4: 557.94 \pm 38.44$ vs. 514.22 $\pm 43.47 p<0.01$ and $78.59 \pm 6.73$ vs. $88.61 \pm 9.37 p<$ 0.001). However, in the Control group, only an improvement of $6 \mathrm{MW}$ was found at 4 weeks and was smaller than the PR group. At 12 and 24 weeks, 6MW and HR were similar in two groups.

The measurements of FVC and $\mathrm{FEV}_{1}$ is shown in Table 5. At the time of discharge and week $1, \mathrm{FEV}_{1}$ in the $\mathrm{PR}$ group was significantly larger than that in the Control group. There was no significant difference in FVC between the two groups at week $1(2.05 \pm 0.26$ vs. $1.91 \pm 0.21, p=0.096)$. Although FVC and FEV1 improved significantly in both groups, there was greater improvement in the PR groups than the Control group at week 4. $\mathrm{FEV}_{1}$ and $\mathrm{FVC}$ in the PR group exceeded $80 \%$ of predicted values at 4 weeks [FVC (\% predicted): $86.27 \pm 9.14$ vs. $78.87 \pm 7.55$, $p<0.05$; FEV1 (\% predicted) $88.76 \pm 6.22$ vs. $78.96 \pm 6.91, p<$ $0.001]$. At 12 and 24 weeks, there were no significant difference in
TABLE 1 | General characteristics in PR and control groups.

\begin{tabular}{|c|c|c|c|}
\hline & \multicolumn{2}{|c|}{ No. (\%) } & \multirow[t]{2}{*}{$p$-value } \\
\hline & $\begin{array}{l}\text { PR Group } \\
(n=63)\end{array}$ & $\begin{array}{l}\text { Control Group } \\
(n=60)\end{array}$ & \\
\hline Age (years) & $36.59 \pm 7.01$ & $35.47 \pm 7.58$ & 0.40 \\
\hline Gender & & & 0.53 \\
\hline Male & 34 & 29 & \\
\hline Female & 29 & 31 & \\
\hline \multicolumn{4}{|l|}{$\begin{array}{l}\text { Blood pressure ( } \mathrm{mmHg} \text {, at } \\
\text { discharge) }\end{array}$} \\
\hline Systolic pressure & $116.3 \pm 4.4$ & $115.8 \pm 5.2$ & 0.57 \\
\hline Diastolic pressure & $78.7 \pm 3.2$ & $78.1 \pm 3.5$ & 0.32 \\
\hline Weight (kg, at discharge) & $62.4 \pm 11.3$ & $64.0 \pm 10.9$ & 0.43 \\
\hline Height (cm, at discharge) & $167.6 \pm 13.2$ & $167.8 \pm 12.9$ & 0.93 \\
\hline \multicolumn{4}{|l|}{ Personal habits } \\
\hline Smoking & $7(11.1)$ & $9(15.0)$ & 0.52 \\
\hline Drinking & $4(6.3)$ & $3(5.0)$ & 0.75 \\
\hline Education & & & 0.66 \\
\hline Junior high school or below & 12 & 9 & \\
\hline High school or vocational school & 19 & 24 & \\
\hline College degree & 16 & 17 & \\
\hline Bachelor degree & 12 & 8 & \\
\hline Postgraduate degree or above & 4 & 2 & \\
\hline
\end{tabular}

$P R$, pulmonary rehabilitation.

$\mathrm{FEV}_{1}$ and FVC between two groups and FEV1 and FVC reached $90 \%$ of predicted values. There was no significant change in $\mathrm{FEV}_{1}$ to FVC ratio during the entire follow-up period. 
TABLE 2 | Clinical characteristics in PR and control groups.

\begin{tabular}{lccc}
\hline & \multicolumn{2}{c}{ No. (\%) } & p-value \\
\cline { 2 - 3 } & $\begin{array}{c}\text { PR Group } \\
(\boldsymbol{n}=\mathbf{6 3})\end{array}$ & $\begin{array}{c}\text { Control Group } \\
(\boldsymbol{n}=\mathbf{6 0})\end{array}$ \\
\hline Clinical Presentation & & & \\
Fever & $62(98.8)$ & $59(98.3)$ & 1.00 \\
Dry cough & $45(71.4)$ & $41(68.3)$ & 0.71 \\
Headache & $5(7.9)$ & $4(6.7)$ & 1.00 \\
Sore throat & $7(11.1)$ & $5(8.3)$ & 0.40 \\
Myalgia & $21(33.3)$ & $18(30.0)$ & 0.69 \\
Fatigue & $24(38.1)$ & $19(31.7)$ & 0.46 \\
Dyspnoea & $28(44.4)$ & $21(35.0)$ & 0.29 \\
Rhinorrhoea & $13(20.6)$ & $11(18.3)$ & 0.75 \\
Nausea \& vomiting & $18(28.6)$ & $19(31.7)$ & 0.71 \\
Diarrhea & $12(19.0)$ & $10(16.7)$ & 0.73 \\
Length of Hospital stay (days) & $21.18 \pm 4.98$ & $21.94 \pm 3.24$ & 0.32 \\
\cline { 1 - 3 } & &
\end{tabular}

$P R$, pulmonary rehabilitation.

$\mathrm{DL}_{\mathrm{CO}}$ was shown in Table 6. At the first week after discharge, no improvements were discovered in $\mathrm{DL}_{\mathrm{CO}}$. Meanwhile, the $\mathrm{DL}_{\mathrm{CO}}$ of PR group was higher than Control group (19.65 \pm 2.12 vs. $17.03 \pm 1.94, p<0.01$ ). Significant improvements were discovered at 4 weeks, while level of $\mathrm{DL}_{\mathrm{CO}}$ in the PR group was higher than the Control group [DLCO (\% predicted): $87.27 \pm$ 6.20 vs. $77.78 \pm 5.85, p<0.001]$. At 12 and 24 weeks, $\mathrm{DL}_{\mathrm{CO}}$ reached normal level and had no significantly differences between two groups.

As shown in Figure 2, in the PR group, little parenchymal bands with group-glass opacity were observed at the time of discharge in all patients. The lesions of 49 patients (77.8\%) in PR group basically disappeared at 4 weeks follow-up and no changes were discovered at 24 weeks. The CT images of 60 patients (95.2\%) in PR group were basically normal at 24 weeks. In the control group, little parenchymal bands with more groupglass opacities were observed at the time of discharge in all patients. At 4 weeks follow-up, some group-glass opacities still existed in CT images of 32 patients (53.3\%). The lesions of only 28 patients (46.7\%, $p=0.0004$ vs. PR group) in control group basically disappeared at 4 weeks follow-up and no changes were discovered at 24 weeks. The CT images of 56 patients (93.3\%, $p=0.65$ vs. PR group) in control group were basically normal at 24 weeks.

\section{DISCUSSION}

The main physiological change in patient recovery from COVID19 is poorer cardio-pulmonary function, and lower FVC, $\mathrm{FEV}_{1}$, and $\mathrm{DL}_{\mathrm{CO}}$. Meanwhile most of the values of $\mathrm{FEV}_{1} / \mathrm{FVC}$ were still abnormal. The main imaging changes from CT scanning were little parenchymal bands with residual group-glass opacity. As a result, the pathologic changes in the lung of patients after discharge might be: (1) residual unabsorbed exudative lesion; (2) mild lung fibrosis. These changes result in the
TABLE 3 | Results of laboratory examination at discharge.

\begin{tabular}{|c|c|c|c|}
\hline & $\begin{array}{l}\text { PR Group } \\
(n=63)\end{array}$ & $\begin{array}{l}\text { Control Group } \\
\quad(n=60)\end{array}$ & $p$-value \\
\hline \multicolumn{4}{|l|}{ Blood Count } \\
\hline WBC $\left(\times 10^{9} / L\right)$ & $7.14 \pm 3.41$ & $6.86 \pm 2.99$ & 0.63 \\
\hline Lymphocyte count $\left(\times 10^{9} / \mathrm{L}\right)$ & $0.62 \pm 0.08$ & $0.66 \pm 0.09$ & 0.20 \\
\hline PLT at discharge $\left(\times 10^{9} / \mathrm{L}\right)$ & $243 \pm 99$ & $216 \pm 71$ & 0.09 \\
\hline Hemoglobin $(\mathrm{g} / \mathrm{dL})$ & $118 \pm 23$ & $125 \pm 17$ & 0.10 \\
\hline \multicolumn{4}{|l|}{ Coagulation Function } \\
\hline $\mathrm{PT}(\mathrm{s})$ & $14.1 \pm 3.3$ & $13.2 \pm 1.4$ & 0.08 \\
\hline $\mathrm{APTT}(\mathrm{s})$ & $37.6 \pm 9.0$ & $37.2 \pm 6.2$ & 0.82 \\
\hline D-dimer (mg/L) & $1.7 \pm 2.4$ & $1.3 \pm 1.9$ & 0.24 \\
\hline \multicolumn{4}{|l|}{ Blood Biochemistry } \\
\hline $\mathrm{TP}(\mathrm{g} / \mathrm{L})$ & $64.5 \pm 10.3$ & $66.5 \pm 7.2$ & 0.21 \\
\hline Albumin (g/L) & $34.6 \pm 5.8$ & $37.5 \pm 6.4$ & 0.10 \\
\hline ALT (U/L) & $35 \pm 19$ & $40 \pm 22$ & 0.14 \\
\hline AST (U/L) & $30 \pm 15$ & $34 \pm 19$ & 0.20 \\
\hline TB $(\mu \mathrm{mol} / \mathrm{L})$ & $11.8 \pm 5.5$ & $12.5 \pm 6.2$ & 0.51 \\
\hline Sodium (mmol/L) & $137.7 \pm 5.3$ & $138.5 \pm 3.3$ & 0.30 \\
\hline Potassium (mmol/L) & $4.1 \pm 0.5$ & $3.9 \pm 0.4$ & 0.09 \\
\hline Creatinine $(\mu \mathrm{mol} / \mathrm{L})$ & $71.2 \pm 27.5$ & $69.1 \pm 20.4$ & 0.62 \\
\hline $\mathrm{BUN}(\mathrm{mmol} / \mathrm{L})$ & $5.2 \pm 2.1$ & $5.4 \pm 2.3$ & 0.66 \\
\hline $\mathrm{LDH}(\mathrm{U} / \mathrm{L})$ & $239 \pm 133$ & $213 \pm 127$ & 0.27 \\
\hline CK-MB (U/L) & $10.9 \pm 8.5$ & $11.8 \pm 7.7$ & 0.53 \\
\hline \multicolumn{4}{|l|}{ Infection-Related Biomarkers } \\
\hline $\mathrm{CRP}(\mathrm{mg} / \mathrm{L})$ & $23 \pm 34$ & $18 \pm 25$ & 0.34 \\
\hline РCT (ng/ml) & $0.18 \pm 0.45$ & $0.11 \pm 0.18$ & 0.21 \\
\hline
\end{tabular}

$P R$, pulmonary rehabilitation; $R B C$, red blood cell, WBC, white blood cell; $P T$, prothrombin time; PLT, platelet; APTT, activated partial thromboplastin time; FBG, fasting blood glucose; TP, total protein; ALT, alanine transaminase; AST, aspertate aminotransfera; TB, total bilirubin; $B U N$, blood urea nitrogen; $L D H$, lactate dehydrogenase; $C K-M B$, creatine kinase-MB; CRP, hypersensitive C-reactive protein; $P C T$, procalcitonin.

functional disorders include: (1) decreasing in lung capacity; (2) decreasing in lung compliance; (3) decreasing in diffusion function. However, all impairments disappeared within 12 weeks, which means the pathological and functional changes are reversible.

The residual lesions of lung function are not rarely in viral pneumonia. Studies have discovered that survivors from SARS had significantly impaired pulmonary function, limited physical and psychology function, and reduced life quality $(11,12)$. Regarding influenza A virus H1N1, a study found that over half of these patients had signs of more severe abnormal pulmonary function, including diffusion disorders and small airway dysfunction, 1 year after discharge (13). From our results, we found that the residual lesions of lung function caused by SARS-CoV-2 is relatively short-term and reversible. It might attribute to the relatively lower virulence of the virus or the participants we included were not severe and critical.

Pulmonary rehabilitation is a comprehensive intervention that includes but is not limited to exercise training, education and behavioral changes with the aim to improve the physical and psychological conditions of people with respiratory disease 
TABLE 4 | Six-min walk distance and heart rate.

\begin{tabular}{|c|c|c|c|c|c|}
\hline & Discharge & 1 week & 4 weeks & 12 weeks & 24 weeks \\
\hline \multicolumn{6}{|l|}{$6 \mathrm{MW}(\mathrm{m})$} \\
\hline PR group & $462.12 \pm 31.61$ & $495.88 \pm 34.67^{\star}$ & $557.94 \pm 38.44^{\star} \dagger$ & $584.41 \pm 20.12^{*} \dagger$ & $598.71 \pm 22.35^{\star} \dagger \neq$ \\
\hline Control group & $448.56 \pm 31.10$ & $470.83 \pm 35.70$ & $514.22 \pm 43.47^{* \dagger}$ & $573.11 \pm 29.20^{*} \dagger \neq$ & $590.33 \pm 19.88^{*}+\ddagger$ \\
\hline PR vs. control & $p>0.05$ & $p<0.05$ & $p<0.01$ & $p>0.05$ & $p>0.05$ \\
\hline$p$ and $\eta^{2}$ for ANOVA & \multicolumn{5}{|c|}{ 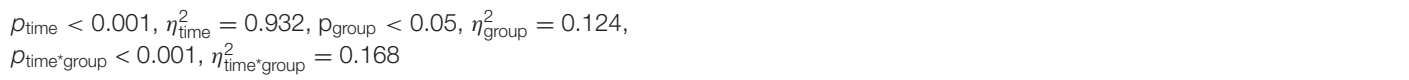 } \\
\hline \multicolumn{6}{|l|}{ HR (beats/min) } \\
\hline PR group & $90.71 \pm 9.30$ & $83.24 \pm 8.46^{\star}$ & $78.59 \pm 6.73^{\star}$ & $76.06 \pm 6.09^{\star} \dagger$ & $76.06 \pm 6.09^{\star} \dagger$ \\
\hline Control group & $97.44 \pm 10.39$ & $97.05 \pm 14.24$ & $88.61 \pm 9.37$ & $78.61 \pm 9.37^{*} \ddagger \ddagger$ & $77.00 \pm 6.16^{\star} \dagger \ddagger$ \\
\hline PR vs. control & $p=0.052$ & $p<0.001$ & $p<0.001$ & $p>0.05$ & $p>0.05$ \\
\hline$p$ and $\eta^{2}$ for ANOVA & \multicolumn{5}{|c|}{$\begin{array}{l}p_{\text {time }}<0.001, \eta_{\text {time }}^{2}=0.778, p_{\text {group }}<0.05, \eta_{\text {group }}^{2}=0.143 \\
p_{\text {time }} \text { group }<0.001, \eta_{\text {time*group }}^{2}=0.332\end{array}$} \\
\hline
\end{tabular}

PR, pulmonary rehabilitation; $6 \mathrm{MW}, 6$-min walk distance; HR, heart rate.

$P$-value of PR. vs. Control was from Student's t-test between two groups.

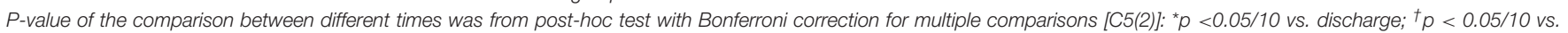

1 week; ${ }^{\ddagger} p<0.05 / 10$ vs. 4 weeks.

TABLE 5 | Forced vital capacity and forced expiratory volume in $1 \mathrm{~s}$.

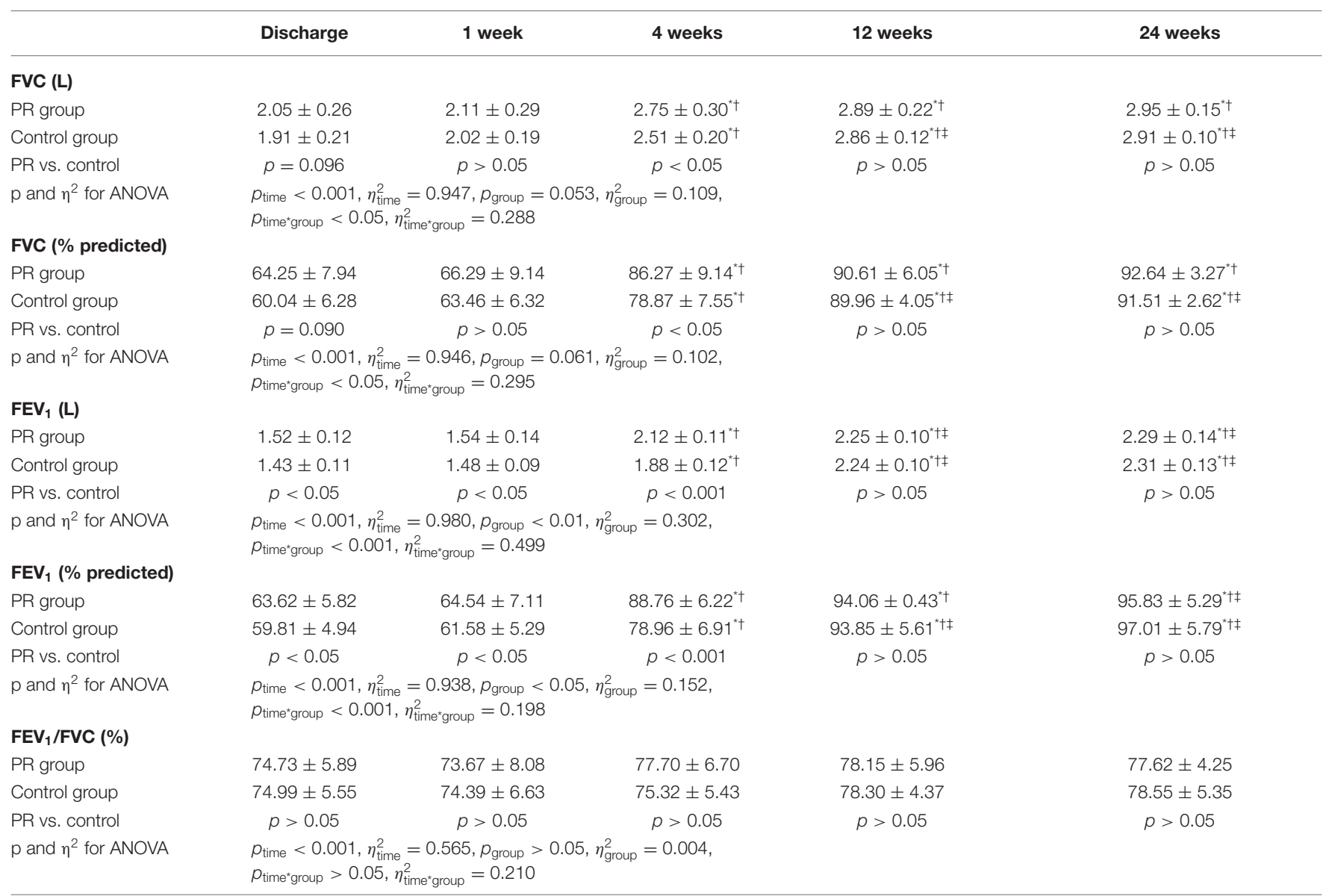

$P R$, pulmonary rehabilitation; $F V C$, forced vital capacity; FEV1, forced expiratory volume in $1 \mathrm{~s}$.

$P$-value of PR. vs. Control was from Student's $t$-test between two groups.

$P$-value of the comparison between different times was from post-hoc test with Bonferroni correction for multiple comparisons [C5(2)]: ${ }^{*} p<0.05 / 10 \mathrm{vs.} \mathrm{discharge;}{ }^{t} p<0.05 / 10 \mathrm{vs}$.

1 week; ${ }^{\ddagger} p<0.05 / 10$ vs. 4 weeks. 
TABLE 6 | Diffusing capacity of the lung for carbon monoxide.

\begin{tabular}{|c|c|c|c|c|c|}
\hline & Discharge & 1 week & 4 weeks & 12 weeks & 24 weeks \\
\hline \multicolumn{6}{|c|}{$\mathrm{DL}$ co $[\mathrm{ml} /(\mathrm{min} \cdot \mathrm{mmHg})]$} \\
\hline PR group & $18.53 \pm 2.03$ & $19.65 \pm 2.12$ & $21.76 \pm 2.19^{\star}$ & $22.88 \pm 2.12^{\star} \dagger$ & $22.94 \pm 2.33^{\star} \dagger$ \\
\hline Control group & $16.00 \pm 1.46$ & $17.03 \pm 1.94^{*}$ & $18.83 \pm 1.86^{\star}$ & $21.50 \pm 2.38^{\star} \dagger \ddagger$ & $22.72 \pm 2.16^{\star} \dagger \ddagger$ \\
\hline PR vs. control & $p<0.001$ & $p<0.01$ & $p<0.001$ & $p=0.079$ & $p>0.05$ \\
\hline$p$ and $\eta^{2}$ for ANOVA & \multicolumn{5}{|c|}{$\begin{array}{l}p_{\text {time }}<0.001, \eta_{\text {time }}^{2}=0.753, p_{\text {group }}<0.01, \eta_{\text {group }}^{2}=0.271 \\
p_{\text {time*group }}<0.01, \eta_{\text {time }}^{2} \text { group } \\
=0.145\end{array}$} \\
\hline \multicolumn{6}{|l|}{ DLco (\% predicted) } \\
\hline PR group & $74.36 \pm 6.59$ & $78.81 \pm 6.57$ & $87.27 \pm 6.20^{\star} \dagger$ & $91.99 \pm 8.73^{*} \dagger$ & $92.12 \pm 8.32^{*} \dagger$ \\
\hline Control group & $66.24 \pm 6.20$ & $70.32 \pm 7.46$ & $77.78 \pm 5.85^{\star} \dagger$ & $88.57 \pm 5.037^{*}+\ddagger$ & $93.94 \pm 8.29^{*} \dagger$ \\
\hline PR vs. control & $p<0.01$ & $p<0.01$ & $p<0.001$ & $p>0.05$ & $p>0.05$ \\
\hline$p$ and $\eta^{2}$ for ANOVA & \multicolumn{5}{|c|}{$\begin{array}{l}p_{\text {time }}<0.001, \eta_{\text {time }}^{2}=0.740, p_{\text {group }}<0.01, \eta_{\text {group }}^{2}=0.283 \\
p_{\text {time }}=0.01, \eta_{\text {time }}^{2} \text { group } \\
=0.143\end{array}$} \\
\hline
\end{tabular}

$P R$, pulmonary rehabilitation; FVC, forced vital capacity; $D L_{C O}$, diffusing capacity of the lung for carbon monoxide.

$P$-value of PR. vs. Control was from Student's t-test between two groups.

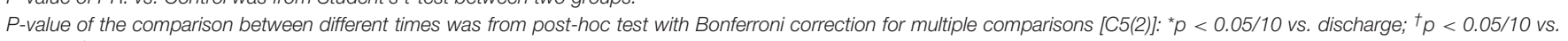
1 week; ${ }^{\ddagger} p<0.05 / 10$ vs. 4 weeks.

and promote long-term quality of life (6). Previous studies have confirmed the positive effects of pulmonary rehabilitation on pulmonary diseases such as COPD and H1N1 pneumonia $(8,12$, 14). Besides, pulmonary rehabilitation has been proved to benefit the lung function and life quality in interstitial lung diseases such as idiopathic pulmonary fibrosis and interstitial pneumonias (1517). Based on clinical practice, the program of pulmonary mainly contained three aspects: (1) physical training, (2) respiratory training, and (3) psychological regulation. Therefore, there are three main benefits of PR: (1) improve the patients' exercise capacity, (2) improve the patients' pulmonary function, and (3) improve the patients' psychological state. During the whole follow-up from the time of discharge to 24 weeks later, we can find that the pulmonary function of PR group was basically normal at 4 weeks, while Control group was basically normal at 12 weeks. As a result, the pulmonary rehabilitation could accelerate the recovery of pulmonary lesions and cardiopulmonary function. According to the changes in CT imaging, we suspected that the effects of pulmonary rehabilitation may attribute to the promotion in absorption of exudation and fibrosis lesions, result in improvement of lung capacity, compliance, and diffusion function.

Because of the flexibility, feasibility and low cost, pulmonary rehabilitation could be a relatively practical way to improve patient condition. Most of patients suffered from COVID-19 are mild and common type, which makes it easy to carry out pulmonary rehabilitation. As for critical patient, whether, when, and how to carry out pulmonary rehabilitation should be further considered. Moreover, the intensity of training relies on the patients' condition; hence, the therapists should pay more attention each patient's vital signs and subjective feelings to not only maximize the effectiveness of the training but also avoid adverse events.

The main limitation of our study is that we only reported the results of 24 weeks follow-up, whether COVID-19 have sequela in respiratory system or other systems should be further studied.

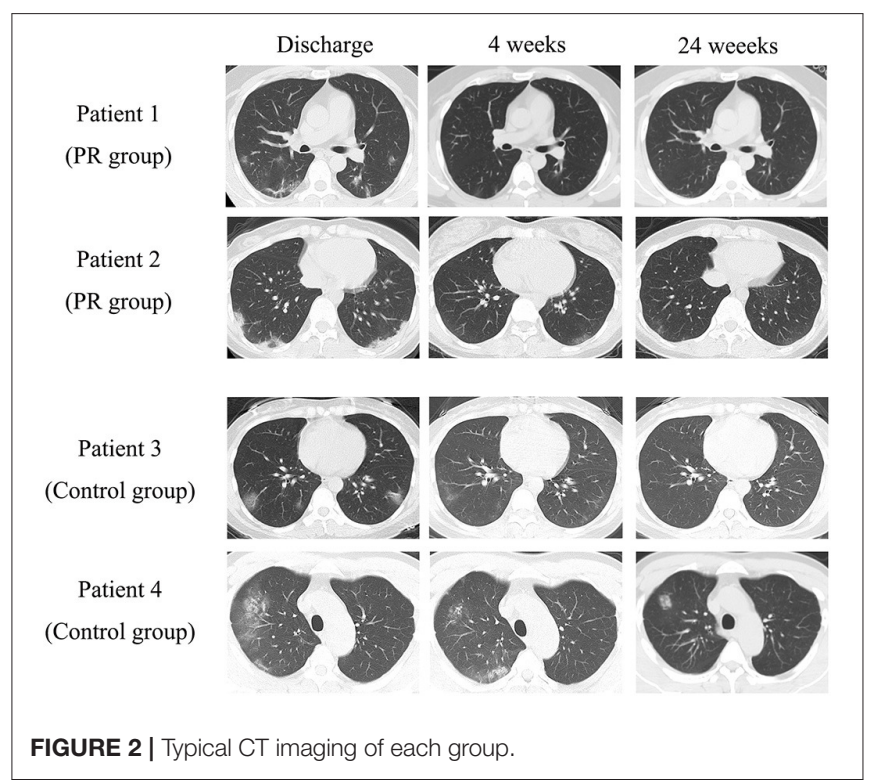

On the other hand, the characteristics of socio-economic of patients might affect patients' choice for accepting pulmonary rehabilitation, which might also lead to a better recovery. However, the socio-economic data were not available, which could be another limitation for this research.

In conclusion, pulmonary rehabilitation could accelerate the recovery of pulmonary function for COVID-19 patients.

\section{DATA AVAILABILITY STATEMENT}

The raw data supporting the conclusions of this article will be made available by the authors, without undue reservation. 


\section{ETHICS STATEMENT}

The studies involving human participants were reviewed and approved by Wuhan Fourth Hospital. The patients/participants provided their written informed consent to participate in this study.

\section{AUTHOR CONTRIBUTIONS}

PZ, HG, and YC conceived and designed the study. YC and $\mathrm{PZ}$ contributed to the literature search. CC, ZF, and AZ contributed to data collection. $\mathrm{AZ}, \mathrm{ZF}$, and $\mathrm{XG}$ contributed to data analysis. $\mathrm{PZ}$ and $\mathrm{XG}$ contributed to data interpretation. ZW contributed to the figures. ZW, HG, and PZ drafted the article. All authors contributed to the article and approved the submitted version.

\section{REFERENCES}

1. Chan JF, Yuan S, Kok KH, To KK, Chu H, Yang J, et al. A familial cluster of pneumonia associated with the 2019 novel coronavirus indicating personto-person transmission: a study of a family cluster. Lancet. (2020) 395:51423. doi: 10.1016/S0140-6736(20)30154-9

2. Chen ZM, Fu JF, Shu Q, Chen YH, Hua CZ, Li FB, et al. Diagnosis and treatment recommendations for pediatric respiratory infection caused by the 2019 novel coronavirus. World J Pediatrics. (2020) 16:2406. doi: 10.1007/s12519-020-00345-5

3. Zhang H, Kang Z, Gong H, Xu D, Wang J, Li Z, et al. The digestive system is a potential route of $2019-\mathrm{nCov}$ infection: a bioinformatics analysis based on single-cell transcriptomes. bioRxiv. 2020.2001.2030.927806 (2020). doi: 10.1101/2020.01.30.927806

4. Lu CW, Liu XF, Jia ZF. 2019-nCoV transmission through the ocular surface must not be ignored. Lancet. (2020) 395:e39. doi: 10.1016/S0140-6736(20)30313-5

5. Spruit MA, Pulmonary rehabilitation. Eur Respir Rev. (2014) 23:5563. doi: 10.1183/09059180.00008013

6. Spruit MA, Singh SJ, Garvey C, ZuWallack R, Nici L, Rochester C, et al. An official American thoracic society/european respiratory society statement: key concepts and advances in pulmonary rehabilitation. Am J Respir Crit Care Med. (2013) 188:e13-64. doi: 10.1164/rccm.201309-1634ST

7. Pehlivan E, Balci A, Kilic L, Kadakal F. Preoperative pulmonary rehabilitation for lung transplant: effects on pulmonary function, exercise capacity, and quality of life; first results in Turkey. Exp Clin Transp. (2018) 16:45560. doi: 10.6002/ect.2017.0042

8. Hsieh MJ, Lee WC, Cho HY, Wu MF, Hu HC, Kao KC, et al. Recovery of pulmonary functions, exercise capacity, and quality of life after pulmonary rehabilitation in survivors of ARDS due to severe influenza A (H1N1) pneumonitis. Influenza Respir Viruses. (2018) 12:6438. doi: 10.1111/irv.12566

9. Snyder EM, Johnson BD, Beck KC. An open-circuit method for determining lung diffusing capacity during exercise: comparison to rebreathe. J Appl Physiol. (2005) 99:1985-91. doi: 10.1152/japplphysiol.00348.2005

10. Wheatley CM, Baker SE, Daines CM, Phan H, Martinez MG, Morgan WJ, et al. Influence of the Vibralung Acoustical Percussor on pulmonary function and sputum expectoration in individuals with cystic fibrosis. Ther Adv Respir Dis. (2018) 12:1753466618770997. doi: 10.1177/1753466618770997

\section{FUNDING}

This study was funded by National Natural Science Foundation of Wuhan (Grant Nos. WX18Q21 and WX19Q24); Health commission of Hubei Province scientific research project (Grant No. WJ2019H371); and The National Natural Science Foundationof Hubei (Grant No. 2019CFB806). We acknowledge the financial support from the National Institute for Health Research, UK (ICA-CL-2018-04-ST2-012) to HG and by British Heart Foundation, UK (PG/19/23/34259) to HG.

\section{ACKNOWLEDGMENTS}

We are grateful for all our colleagues for their support of the present study. We are also grateful to the many front-line medical staffs for their dedication in the face of this outbreak, despite the potential threat to their own lives and the lives of their families.

11. Ngai JC, Ko FW, Ng SS, To KW, Tong M, Hui DS. The long term impact of severe acute respiratory syndrome on pulmonary function, exercise capacity and health status. Respirology. (2010) 15:543-50. doi: 10.1111/j.1440-1843.2010.01720.x

12. Herridge MS, Tansey CM, Matte A, Tomlinson G, Diaz-Granados N, Cooper A, et al. Functional disability 5 years after acute respiratory distress syndrome. N Engl J Med. (2011) 364:1293-304. doi: 10.1056/NEJMoa10 11802

13. Liu W, Peng L, Liu H, Hua S. Pulmonary function and clinical manifestations of patients infected with mild Influenza A virus subtype H1N1: a oneyear follow-up. PloS ONE. (2015) 10:e0133698. doi: 10.1371/journal.pone.01 33698

14. Carreiro A, Santos J, Rodrigues F. Impact of comorbidities in pulmonary rehabilitation outcomes in patients with chronic obstructive pulmonary disease. Rev Port Pneumol. (2013) 19:106-113. doi: 10.1016/j.rppnen.2012.12.001

15. Dowman L, Hill CJ, Holland AE. Pulmonary rehabilitation for interstitial lung disease. Cochrane Database Syst Rev. (2014) Cd006322. doi: 10.1002/14651858.CD006322.pub3

16. Vainshelboim B, Oliveira J, Yehoshua L, Weiss I, Fox BD, Fruchter $\mathrm{O}$, et al. Exercise training-based pulmonary rehabilitation program is clinically beneficial for idiopathic pulmonary fibrosis. Respir. (2014) 88:37888. doi: 10.1159/000367899

17. Yu X, Li X, Wang L, Liu R, Xie Y, Li S, et al. Pulmonary rehabilitation for exercise tolerance and quality of life in IPF patients: a systematic review and meta-analysis. BioMed Res Int. (2019) 2019:8498603. doi: $10.1155 / 2019 / 8498603$

Conflict of Interest: The authors declare that the research was conducted in the absence of any commercial or financial relationships that could be construed as a potential conflict of interest.

Copyright (C) 2021 Zhu, Wang, Guo, Feng, Chen, Zheng, Gu and Cai. This is an open-access article distributed under the terms of the Creative Commons Attribution License (CC BY). The use, distribution or reproduction in other forums is permitted, provided the original author(s) and the copyright owner(s) are credited and that the original publication in this journal is cited, in accordance with accepted academic practice. No use, distribution or reproduction is permitted which does not comply with these terms. 